\title{
Changes in Volatile Profiles and Activity of Hydroperoxide Lyase and Alcohol Dehydrogenase During the Development of Cabernet Sauvignon Grapes (Vitis vinifera L.)
}

\author{
Ya Nan' OuYang ${ }^{1}$, Jin Shan Gao ${ }^{1}$, Ruo Lan $\mathrm{Li}^{1}$, Mei Rong Zhu ${ }^{1}$, Xin Hao Hu${ }^{1}$, Zhuo Min ${ }^{1}$, Shu Xia Chen², Zhen Wen Zhang ${ }^{1,3}$, \\ Yu Lin Fang ${ }^{1,3^{*}}$ \\ (1) College of Oenology, Northwest A\&F University, Yangling, Shaanxi 712100, China \\ (2) College of Horticulture, Northwest A\&F University, Yangling, Shaanxi 712100, China \\ (3) Grape and Wine Engineering Research Centre in Shaanxi Province, Yangling, Shaanxi 712100, China
}

Submitted for publication: April 2015

Accepted for publication: October 2015

Key words: Alcohol dehydrogenase, Cabernet Sauvignon, hydroperoxide lyase, volatiles

\begin{abstract}
In this study we focused on the development of Cabernet Sauvignon grapes and investigated changes in the activity of alcohol dehydrogenase (ADH) and hydroperoxide lyase (HPL) in different tissues. We sampled grape skin at four, six, seven, eight, nine, 10, 12, 14 and 16 weeks after anthesis; developing flowers when blooming at $0 \%, 5 \%, 50 \%$, and $90 \%$; and leaves at two and four weeks before anthesis and at two, four, six, eight, nine, and 10 weeks after anthesis. We also examined the type and fluctuation of volatile contents. ADH activity increased with the development of flowers and grape skins, which led to the increasing of types and concentration of alcohols. Low levels of 9-HPL led to low concentrations of C9 compounds. According to this paper, $\mathrm{C} 6$ compounds became abundant with the development of grape berries, while the activity of 13-HPL kept at a low level in the flowers and grape skins. There might have been a high level of 13-HPL activity from the end of flowering until fruit setting that we did not detect. Furthermore, similar C6 and C5 compounds were detected across all tissues, including hexanal, (E)-2-hexenal, (Z)-3-hexenal, (Z)-2-penten-1-ol, (Z)-3-hexen-1-ol, 1-hexanol and 3-hexen-1-ol. Generally speaking, the concentrations of C6 and $\mathrm{C} 5$ compounds could be used as the criterion of maturation of the three grape tissues.
\end{abstract}

\section{INTRODUCTION}

Green leaf volatiles (GLVs) are short-chain acyclic aldehydes, alcohols and esters that form as a result of the catalysis by hydroperoxide lyases (HPLs) and alcohol dehydrogenase $(\mathrm{ADH})$, and they are the main source of the green aroma in grapes. GLVs are known for the aroma of crushed or injured leaves (Hatanaka, 1993; Matsui et al., 2006), and plants produce GLVs after damage and biotic or abiotic stress. GLVs are not only the main source of volatiles in fruit and vegetables - they also have important physiological functions. They are critical signals that help plants recognise and compete with other organisms (Matsui et al., 2006) and also impart resistance to pathogenic bacteria and insects (Nakamura \& Hatanaka, 2002; Tufariello et al., 2012). Furthermore, GLVs are similar to the aroma from spices in the food and beverage industry (Kalua \& Boss, 2009).

The presence of short-chain volatiles in grape juice and wine, as well as their contribution to the final flavour and aromatic composition of wine, has been well documented
(Baumes et al., 1988; Terrier et al., 1996). The major components of these short-chain volatiles are aldehydes, alcohols and esters. They are primarily synthesised via the metabolic pathway of aliphatic acid (Fig. 1S) (Cynthia \& Kenji, 2014). During the maturation of the grape berry, the metabolism of aliphatic acid can be catalysed directly by lipoxygenase (LOX) and the following steps of metabolism are similar to the GLV synthesis pathway described above.

In a previous study, the volatiles formed during the development of three types of non-aromatic grape cultivars revealed that only C6 volatile compounds were present in high concentrations; therefore, changes in the proportion of C6 volatile compounds can be used to confirm optimum maturity of the fruit (Gomez et al., 1995). Other studies revealed that the proportion of volatiles increased significantly after grape colouring (Park et al., 1991; Coelho, et al., 2007). The major C6 volatiles found during the early, middle and late periods of grape development are acetates, aldehydes and alcohols respectively. The ratio of alcohols to aldehydes influences the aroma of grapes and wines. Thus,

*Corresponding author: Yu Lin Fang, E-mail address: fangyulin@nwsuaf.edu.cn

Acknowledgements: The authors would like to express their gratitude to the Programme of State Forestry Administration, 948 Project [2009-4-09]; The National Eleventh Five-year Research Programme of China [2012BAD31B07]; and the National Technology System for Grape Industry [nycytx-30-2p-04], for the generous financial support provided for this work. 
changes in volatiles during grape development indicate greater dependence on enzyme activity and specificity than on the unsaturated fatty acids.

LOX-HPL is the confirmed pathway for GLV formation and, in many other species, it is dependent on the activity of ADH and HPLs. The dependence on LOX, HPLs, ADH, acetyltransferase (AAT) and aldehyde isomerase (AH) in the LOX pathway during grape development allows for the control of grape and wine aroma (Kalua \& Boss, 2009). Moreover, several studies have suggested that most unsaturated fatty acids are metabolised through the 13-HPL pathway during the maceration of grape must (Hashizume \& Samuta, 1997; Coelho et al., 2007; Jiang et al., 2011). Moreover, the pleasant flavours in cucumbers (Cucumis sativus) result from the enzymatic action of LOX on linolenic acid and linoleic acid. LOX introduces molecular oxygen at the $\mathrm{C} 13$ or $\mathrm{C} 9$ of linoleic acid or linolenic acid, thereby forming 13-hydroperoxylinolenic acid (13-HPOT) or 9-hydroperoxylinolenic acid (9-HPOT). HPL cleaves 13HPO (13-hydroperoxide) and 9-HPO (9-hydroperoxide), producing C6 and C9 aldehydes, which are responsible for the flavours in cucumber (Matsui et al., 2000).

In contrast to other plants, very few studies have examined the formation and regulation of GLVs in grapes, especially for Cabernet Sauvignon, which is one of the most important Vitis vinifera varieties cultivated in China. Our study focused on the changes in the activity of $\mathrm{ADH}$ and HPLs, as well as on the development of the characteristic aromatic compounds, to investigate the relationship between key enzyme activity and volatile contents. Our research will enhance our understanding of the enzymes involved in the formation of GLVs during the development of characteristic grape aromas. It will lead to the establishment of links between changes in grapevine physiology and wine quality.

\section{MATERIALS AND METHODS \\ Plant material and sampling}

The Cabernet Sauvignon ( $V$. vinifera $L$.) grapes grown at the Caoxinzhuang vineyard (Yangling, Shaanxi Province, China) were planted in March 2008. Samples were collected during anthesis and grape development from April to May and July to September 2012 respectively. Grape berries were randomly sampled four to 16 weeks after anthesis, and flowers were collected randomly during inflorescence $(0,5,50$ and $90 \%$ florets flowering per cluster). The third to fifth leaves from the bottom of the shoots were collected two and four weeks before anthesis, as well as two, four, six, eight, nine and 10 weeks after anthesis. The five-point random sampling method was used (picking four points with the same distance from the centre point of diagonal lines) for each replicate and there were three replicates. Approximately 30 standard clusters, 30 leaves and 15 inflorescence were sampled at each stage or time point, and the grape berries were separated from the bunches. The grape berries were snap-frozen in liquid nitrogen, and the grape skins were separated from the berries and transferred to a tube. Leaves and flowers were immediately snap-frozen in liquid nitrogen and stored at $-80^{\circ} \mathrm{C}$.

\section{Analysis of enzyme activity}

For enzyme extraction from the HPLs, the sample (1 g) was pulverised in liquid nitrogen and dissolved in a sodium acetate buffer $(3 \mathrm{~mL} ; 50 \mathrm{mM}, \mathrm{pH} 5.0$, containing $0.21 \%$ vitamin $\mathrm{C}$ and $0.5 \%[\mathrm{w} / \mathrm{v}]$ Triton $\mathrm{X}-100)$. The sample was then centrifuged at $14000 \times g$ and $4^{\circ} \mathrm{C}$ for $20 \mathrm{~min}$. The supernatant liquid was the crude extract of the HPL enzyme.

To extract the potato 9-LOX protein, a slice of potato was ground into slurry using liquid nitrogen and dissolved in a $50 \mathrm{mM}$ potassium phosphate buffer $(\mathrm{pH} 7.0$ with $2 \mathrm{mM}$ sodium hydrogen sulphite). The solution was then centrifuged at $12000 \times g$ for $30 \mathrm{~min}$, and ammonium sulphate was added to the resultant supernatant over a $2 \mathrm{~h}$ stirring period to obtain $50 \%$ saturation. After centrifugation, the pellet was re-suspended in a $50 \mathrm{mM}$ potassium phosphate buffer $(\mathrm{pH} 7.0)$ and dialysed overnight using a $50 \mathrm{mM}$ potassium phosphate buffer ( $\mathrm{pH}$ 7.0) and water. All work was performed at $4^{\circ} \mathrm{C}$ (Suurmeijer et al., 1998) and the protein levels were measured by the Coomassie brilliant blue method (Smith et al., 1985).

The activity of HPLs was determined by adding $50 \mu \mathrm{L}$ of $10 \mathrm{mM}$ NADH, $50 \mu \mathrm{L}$ of $5 \mathrm{U} / \mu \mathrm{L}$ ADH, $420 \mu \mathrm{L}$ of substrate (product of linoleic acid catalysed by soybean 13-LOX [Sigma, Aldrich] or potato 9-LOX protein), and $250 \mu \mathrm{L}$ of crude HPLs enzyme extract to $4.5 \mathrm{~mL}$ of $0.1 \mathrm{M}$ potassium phosphate buffer ( $\mathrm{pH}$ 6.0). The reaction proceeded for $4 \mathrm{~min}$ at $20^{\circ} \mathrm{C}$, and then the absorbance was recorded at $340 \mathrm{~nm}$ for 15 s (Anthon \& Barrett, 2003).

For ADH enzyme extraction, the samples were ground using liquid nitrogen and added to $100 \mathrm{mM}$ MES buffer $(\mathrm{pH}$ 6.5) containing $2 \mathrm{mM}$ DTT and $1 \% \mathrm{w} / \mathrm{v}$ PVPP in a ratio of 1:3 (sample:buffer). The sample was homogenised, filtered by gauze and then centrifuged at $14000 \times g$ and $4^{\circ} \mathrm{C}$ for $20 \mathrm{~min}$. The resulting supernatant was the crude extract of ADHs.

The ADHs activity was determined using $0.05 \mathrm{~mL}$ of $1.6 \mathrm{mM} \mathrm{NADH}, 0.05 \mathrm{~mL}$ of $80 \mathrm{mM}$ acetaldehyde, and $0.1 \mathrm{~mL}$ of crude extract ADHs in $0.8 \mathrm{~mL}$ of $100 \mathrm{mM}$ MES buffer ( $\mathrm{pH}$ 6.5). The absorbance was recorded at $340 \mathrm{~nm}$ for $15 \mathrm{~s}$ (Defilippi et al., 2005). Three biological replicates were analysed in three technical replicates

\section{Analysis of volatile compounds}

The volatile compounds were extracted by headspace-solidphase micro-extraction (HS-SPME) and analysed using a Gas Chromatograph-Mass Spectrometer (GC-MS, TRACE DSQ, Finnigan, USA) according to the methods of Song and Barros (Perestrelo et al., 2011; Song et al., 2012). The grape skin, flowers and leaf samples were ground under liquid nitrogen and the resulting powder $(20 \mathrm{~g})$ was suspended in $20 \mathrm{~mL}$ of water and allowed to soak in the dark for $24 \mathrm{~h}$ at $4^{\circ} \mathrm{C}$ in a nitrogen atmosphere. The mixture was then centrifuged at $8000 \times g$ for $30 \mathrm{~min}$, and the supernatant was used for the volatile analysis.

The extracted liquid $(8 \mathrm{~mL})$ was added to a $15 \mathrm{~mL}$ vial containing $2 \mathrm{~g}$ of $\mathrm{NaCl}$ and $5 \mu \mathrm{L}$ of 4-methyl-2-pentanol (0.93 g/L, internal standards). The vial was sealed and heated to $30^{\circ} \mathrm{C}$ for $10 \mathrm{~min}$. Then, a fibre $(50 / 30 \mu \mathrm{m}$ PSMS/ CAR/DVB, Supelco, USA) that was pre-conditioned at $250^{\circ} \mathrm{C}$ for $1 \mathrm{~h}$ was inserted into the headspace of the vial 
for $40 \mathrm{~min}$. The fibre was subsequently desorbed in the GC injector at $250^{\circ} \mathrm{C}$ for $5 \mathrm{~min}$. Three independent biological replicates were analysed for each sample. The GC-MS was performed with a DB-WAX elastic quartz capillary column, an Xcalibur workstation, and the 2002 NIST Standard Reference Database. The oven temperature was maintained at $40^{\circ} \mathrm{C}$ for $2.5 \mathrm{~min}$, increased to $230^{\circ} \mathrm{C}$ at a rate of $6^{\circ} \mathrm{C} / \mathrm{min}$ and then held at $230^{\circ} \mathrm{C}$ for $7 \mathrm{~min}$. The MS transfer line and ion source temperatures were 230 and $200^{\circ} \mathrm{C}$ respectively. A constant helium flow of $1 \mathrm{~mL} / \mathrm{min}$ was used, and the electron impact mass spectrometric data from the $\mathrm{m} / \mathrm{z} 35$ to 400 range were collected with an ionisation voltage of $70 \mathrm{eV}$, an emission current of $100 \mu \mathrm{A}$, and a detection voltage of $1.4 \mathrm{kV}$. Pentanal, butanoic acid, ethyl ester, hexanal, (E)-2pentenal, heptanal, (E)-2-hexenal, 1-pentanol, (Z)-2-penten1-ol, 1-hexanol, (E)-2-hexen-1-ol, 1-nonanol and (E/Z)6-nonen-1-ol were used as individual standards to make calibration curves. The individual standards were dissolved in ethanol and then diluted with water to obtain a set of serial dilutions to establish the calibration curve. The concentration of volatile compounds for which it was not possible to establish calibration curves were estimated on the basis of the equations of compounds with the same functional group and/or similar numbers of $\mathrm{C}$ atoms. GC data was normalised by the area normalisation method to calculate the component concentration.

\section{Statistical analysis}

Mean values, data normalisation (Z-score), PCA analysis and cluster (TwoStep cluster) analysis were calculated and performed using SPSS (Version 19.0). Heatmap and hierarchical clustering analysis were performed to display the change in concentration and types of volatiles in three different tissues by MeV-4-9-0 using normalised and meancentred data. All data presented were the mean values.

\section{RESULTS AND DISCUSSION}

\section{Changes in volatile compounds in different tissues}

Calibration curves of 12 individual standards are shown in Table S1. In total, 36 volatile compounds were detected in the developing grape skin from the 2012 harvest, including 14 aldehydes, 18 alcohols and 10 C6 compounds (Table 1). A heatmap representation of the volatile profiles of grape skins is shown in Fig. 1, revealing that large numbers of volatiles were highly responsive to the sampling dates. Hexanal, benzaldehyde, furfural, 3-methyl-butanal, 2-methyl-butanal, propanal, 1-heptanol, 1-hexanol, (E)/(Z)-2-hexen-1-ol, etc. were the most abundant volatiles present in the grape skins at 16 weeks after anthesis.

All of the volatile profiles clustered into three categories. The first cluster refers to those whose concentrations were abundant at a later development stage of the grape berries. The concentration of the second cluster was higher at the early stage and included 3,7-dimethyl-1,6-octadien-3-ol, 2-hexanol, borneol, (Z)/(E)-2-heptenal, etc. The third cluster of volatiles contained some $\mathrm{C} 5$ and $\mathrm{C} 6$ compounds and the concentrations of $\mathrm{C} 5, \mathrm{C} 6, \mathrm{C} 9$ aldehyde were abundant at 12 weeks. Many studies have shown that the typical aroma of wine from Cabernet Sauvignon grapes comes from C6 compounds (Xu et al., 2015). Our results reveal that different structures of C6 and C5 compounds occurred at different development stages. Most alcohol compounds were detected at 16 weeks and this was consistent with the pathway of LOX-HPL-ADH. This indicated that the fruity and flowery aromas of grape berries increased with grape development. Conversely, the content of eucalyptol (minty odour) declined with berry development, with the highest amounts occurring in the earlier stages. D-limonene (fresh citrus odour) was only identified during some of the berry development stages and reached its highest content 10 weeks after anthesis. Eucalyptol was the predominant monoterpene in the early stage of berry development, which indicates that it was probably left by the flowers (Delphia et al., 2007; Köllner et al., 2008).

Principle component analysis was applied to interpret the results, and the components are shown in Fig. 2. The first three components explained $70.58 \%$ of the variance, which was caused by the difference in volatile components of the grape skins from different sampling dates. According to the loading plot and the PCA score plot, the concentrations of (E)-2-pentenal, 2,6-dimethyl-4-heptanone, and (E,E)-2,4hexadienal were different in the grape skins sampled at 12 weeks after anthesis than those from other development stages. The compounds 3-hexen-1-ol, borneol, (S)-3-ethyl4-methyl-pentanol and 2-ethyl-furan were associated with samples collected at 14 weeks after anthesis. In addition, 3-methyl-butanal, furfural, benzaldehyde, (E)/(Z)-2-hexen1-ol, 1-heptanol and 1-octanol contributed more to the separation of samples at 16 weeks after anthesis (i.e., at harvest). The results of the PCA analysis are consistent with the heatmap analysis.

Forty volatile compounds were identified in the developing flowers, including six aldehydes and 20 alcohols (Table 2). Two different clusters of volatile profiles are displayed in Fig. 3. One of these contained more aldehydes and alcohols. Fig. 3 shows that the concentrations of aldehydes and alcohols were abundant when the flowers were at the bud stage. The other cluster contained more ketones and terpenes. The concentrations of caryophyllene, $\alpha$-caryophyllene, $\alpha$-farnesene, caryophyllene oxide, 2-tridecanone, cyclopentadecanone, etc. increased at the 50\% blooming stage of the flowers. There also were some C5, C6 and $\mathrm{C} 9$ alcohols in the second cluster, such as 1-penten-3ol, 2-nonanol, 4-methyl-5-hexen-2-ol, cyclopentanol, (Z)2-hexen-1-ol, (E)-2-hexen-1-ol and 1-hexanol. All of the volatiles from the second cluster became abundant at the stage of $5 \%$ flower blooming until full blooming. The contents of the aldehydes and alcohols as important components of green leaf odour generally declined during flower development. Various terpenes were identified in the blooming flowers and reached their highest contents in the 50\% flowering stage (Table 2). Bestmann et al. (1997) showed that limonene and the $\alpha$-terpenes were the monoterpenes typically found in flowers, while eucalyptol and caryophyllene were the highest oxyterpene and sesquiterpene respectively.

PCA analysis revealed that the first three components explained $100 \%$ of the variance, with the first component explaining $50.29 \%$ of the total variability. Fig. 4 shows that caryophyllene, $\alpha$-caryophyllene, $\alpha$-farnesene, caryophyllene oxide, 2-tridecanone, 2-pentadecanone, 8-heptadecene, 
TABLE 1

Volatile compounds in grape skin during development in 2012.

\begin{tabular}{lllllllll}
\multicolumn{10}{c}{ Weeks after anthesis/w } \\
\hline 4 & 6 & 7 & 8 & 9 & 10 & 12 & 14 & 16
\end{tabular}

Compound

symbol

Concentration $(\mu \mathrm{g} / \mathrm{kg})$

\begin{tabular}{|c|c|c|c|c|c|c|c|c|c|c|}
\hline \multicolumn{11}{|l|}{ Aldehydes } \\
\hline Propanal & bs 1 & nd & 0.37 & 0.50 & 0.80 & 1.05 & 1.50 & 1.15 & 1.41 & 1.65 \\
\hline 2-methyl-butanal & bs 2 & nd & 0.42 & 0.65 & 0.82 & 1.05 & 1.29 & 2.19 & 2.44 & 2.60 \\
\hline Pentanal & bs 3 & 4.22 & 5.24 & 4.67 & 6.64 & 40.22 & 16.61 & 16.66 & 9.22 & 9.65 \\
\hline Hexanal & bs 4 & 17.46 & 12.45 & 9.28 & 17.93 & 162.27 & 347.32 & 317.09 & 526.22 & 703.26 \\
\hline (E)-2-pentenal & bs 5 & nd & nd & nd & nd & nd & nd & 1.19 & nd & nd \\
\hline (Z)-3-hexenal & bs 6 & nd & 0.52 & 0.94 & 1.50 & 2.27 & 5.29 & 10.71 & 11.89 & 2.04 \\
\hline 2-methyl-4-pentenal & bs 7 & nd & nd & nd & nd & 105.74 & nd & nd & nd & nd \\
\hline 3-methyl-butanal & bs 8 & nd & 0.42 & 0.88 & 1.91 & 2.03 & 1.29 & 1.89 & 2.44 & 6.03 \\
\hline (E)-2-hexenal & bs 9 & 12.06 & 11.76 & 11.11 & 15.21 & 115.51 & 413.02 & 1964.01 & 762.67 & 377.38 \\
\hline$(\mathrm{Z}) /(\mathrm{E})$-2-heptenal & bs 10 & nd & 0.29 & nd & nd & nd & nd & nd & nd & nd \\
\hline Nonanal & bs 11 & nd & nd & nd & nd & 0.78 & 0.99 & 1.68 & 1.36 & nd \\
\hline Furfural & bs 12 & nd & nd & nd & nd & nd & nd & nd & nd & 1.48 \\
\hline (E,E)-2,4-hexadienal & bs 13 & 1.61 & nd & nd & nd & 1.35 & 2.98 & 8.93 & 1.11 & 1.95 \\
\hline Benzaldehyde & bs 14 & nd & nd & nd & nd & nd & nd & nd & nd & 29.24 \\
\hline \multicolumn{11}{|l|}{ Alcohols } \\
\hline 1-Penten-3-ol & bs 15 & 3.25 & 3.18 & 1.40 & 2.98 & 6.85 & 11.12 & 11.61 & 6.44 & 5.01 \\
\hline 2-Hexanol & bs 16 & 185.97 & 186.00 & nd & nd & 1.31 & 6.78 & 118.00 & 98.78 & 90.40 \\
\hline 3-Methyl-1-butanol & bs 17 & 0.80 & 1.02 & 0.51 & 0.63 & 1.48 & 6.10 & 5.95 & 9.79 & 6.22 \\
\hline 3-Methyl-3-buten-1-ol & bs 18 & nd & nd & nd & nd & 0.96 & 4.00 & 2.38 & 4.44 & nd \\
\hline 1-Pentanol & bs 19 & 0.89 & 1.09 & 0.68 & 0.62 & 1.83 & 6.10 & 5.95 & 9.78 & 6.05 \\
\hline (Z)-2-Penten-1-ol & bs 20 & nd & 6.32 & nd & 4.02 & 9.86 & 15.12 & 17.41 & 11.56 & 9.38 \\
\hline 1-Hexanol & bs 21 & 13.01 & 4.15 & 6.01 & 7.34 & 16.80 & 29.77 & 34.67 & 98.78 & 90.40 \\
\hline 3-Hexen-1-ol & bs 22 & 14.62 & 6.61 & 6.62 & 6.85 & 10.95 & 14.24 & 19.64 & 26.11 & 7.89 \\
\hline (E)/(Z)-2-hexen-1-ol & bs 23 & 6.17 & 1.09 & 2.46 & 2.74 & 7.59 & 19.26 & 41.07 & nd & 54.67 \\
\hline 1-Heptanol & bs 24 & nd & nd & nd & nd & nd & 1.29 & 1.19 & nd & 1.48 \\
\hline 1-Octen-3-ol & bs 25 & 0.72 & 0.46 & 0.71 & nd & 1.09 & 3.39 & 2.53 & 4.00 & 3.90 \\
\hline $\begin{array}{l}\text { 3,7-Dimethyl-1,6- } \\
\text { octadien-3-ol }\end{array}$ & bs 26 & 1.44 & 1.49 & 1.09 & 0.73 & nd & nd & 0.89 & 2.22 & 1.30 \\
\hline 1-Octanol & bs 27 & nd & nd & nd & nd & nd & 2.30 & 2.98 & 4.00 & 4.94 \\
\hline 1-Nonanol & bs 28 & nd & 0.40 & 0.61 & nd & nd & nd & 1.49 & 1.56 & 1.30 \\
\hline Benzyl alcohol & bs 29 & nd & nd & nd & nd & nd & 2.92 & 3.27 & 5.89 & 4.73 \\
\hline Phenylethyl alcohol & bs 30 & nd & nd & nd & nd & 0.70 & 4.82 & 5.21 & 8.44 & 6.12 \\
\hline Borneol & bs 31 & 2.81 & 3.44 & 2.46 & 4.29 & 3.14 & 2.78 & 2.38 & 3.67 & 2.23 \\
\hline $\begin{array}{l}\text { (S)-3-Ethyl-4- } \\
\text { methylpentanol }\end{array}$ & bs 32 & nd & nd & nd & nd & nd & nd & nd & 14.44 & nd \\
\hline \multicolumn{11}{|l|}{ Others } \\
\hline 2-Ethyl-furan & bs 33 & 1.84 & 4.01 & 2.03 & 1.31 & 2.18 & 1.76 & 3.87 & 5.67 & 1.95 \\
\hline Eucalyptol & bs 34 & 20.18 & 15.63 & 3.86 & 1.52 & nd & nd & nd & nd & nd \\
\hline $\begin{array}{l}\text { 2,6-Dimethyl-4- } \\
\text { heptanone }\end{array}$ & bs 35 & 4.64 & 3.24 & 4.39 & 3.56 & 5.41 & 2.85 & 5.66 & 2.67 & 3.71 \\
\hline D-Limonene & bs 36 & 0.78 & nd & nd & nd & nd & 4.34 & nd & 1.56 & nd \\
\hline
\end{tabular}

nd, not detected 


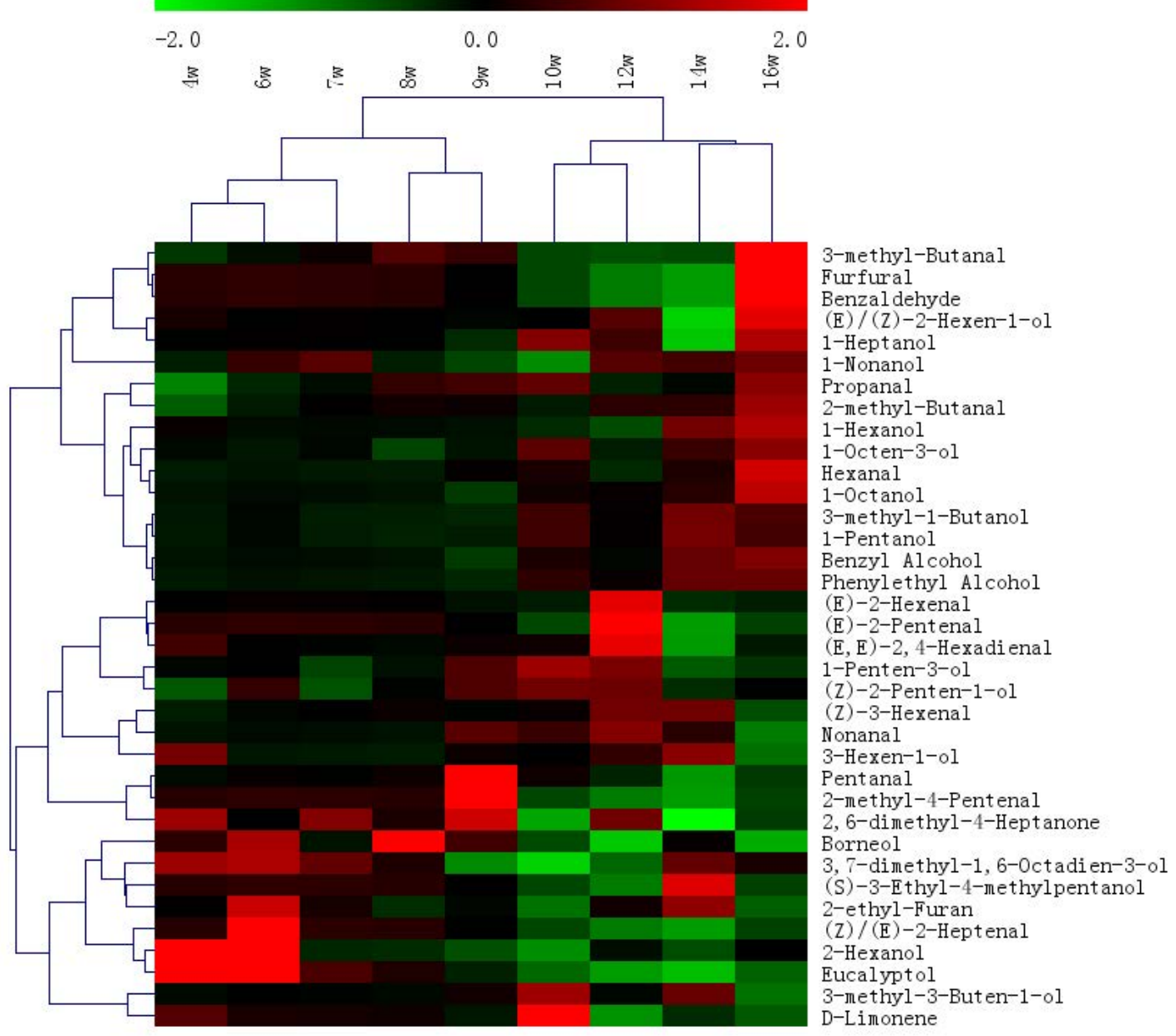

FIGURE 1

Heatmap of the concentration of volatiles in grape skin.

Note: W (weeks after anthesis)

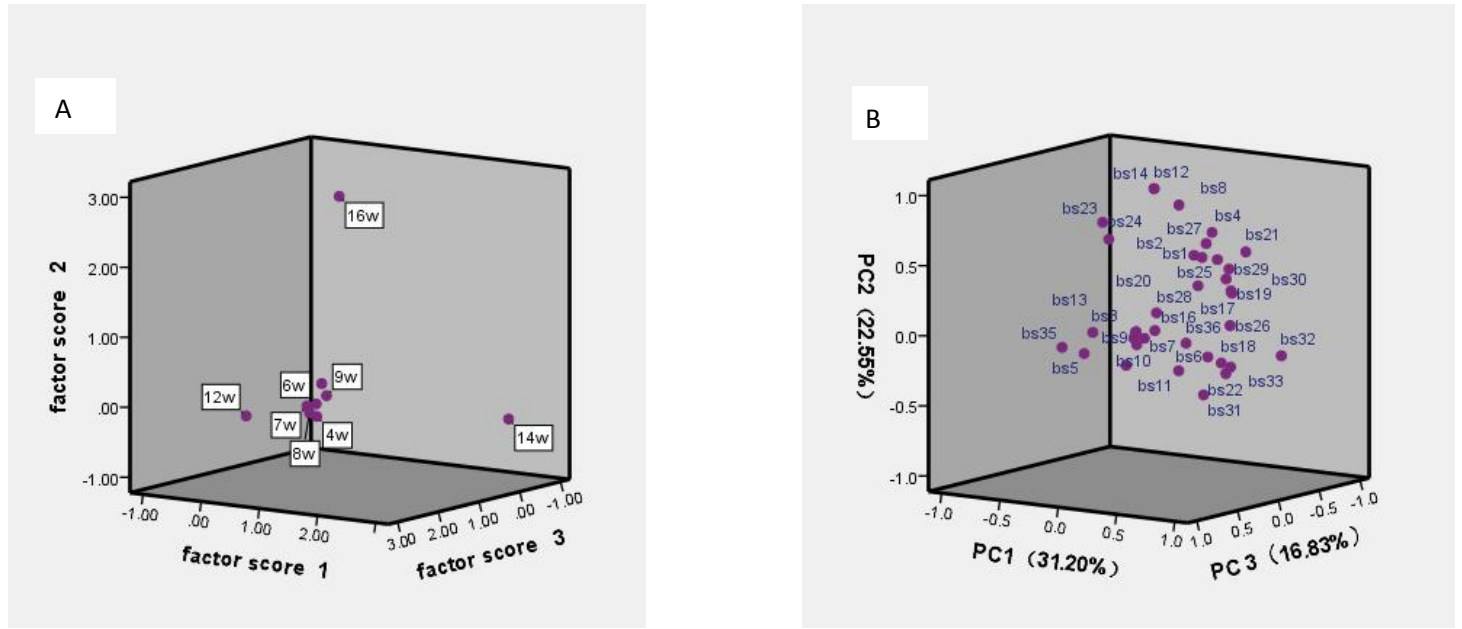

FIGURE 2

Principle component analysis of volatile compounds of grape skin.

A. PCA score plot. B. Loading plot of components 1, 2 and 3.

Note: "bs" refers to volatiles in grape skins. For details, refer to the Table 1.

cyclopentadecanone and cyclotridecanone were major contributors to the variation among flower stages, and could discriminate the $50 \%$ blooming stage from others $(0 \%$, 5\%, 90\%). (E)-2-hexenal, (E,E)-2,4-hexadienal, 2-butyl2-octenal, 2-heptanol, 1-pentanol, 1-heptanol, (R)-3,7dimethyl-6-octen-1-ol, 3,7-dimethyl-2,6-octadien-1-ol and benzyl alcohol contributed more to the volatile composition of the inflorescences, whereas the concentration of these compounds decreased or even declined to zero with the development of flowers.

In the developing leaves, 53 volatile compounds were detected, including 17 aldehydes and 25 alcohols (Table 3). 
TABLE 2

Volatile compounds in flowers during development in 2012.

\begin{tabular}{cccc}
\multicolumn{5}{c}{ Percentage of flowering/\% } \\
\hline 0 & 5 & 50 & 90
\end{tabular}

Compound

Symbol

Concentration $(\mu \mathrm{g} / \mathrm{kg})$

\section{Aldehydes}

Pentanal

\section{F1}

F2

20.67

20.20

nd

nd

Hexanal

(Z)-3-Hexenal

F3

2082.61

184.96

187.09

235.13

(E)-2-Hexenal

(E,E)-2,4-hexadienal

F4

2-Butyl-2-octenal

F5

17.12

21.60

8.70

8.91

Alcohols

Cyclopentanol

944.76

824.46

392.12

349.05

$\begin{array}{ll}\mathrm{F} 5 & 94.48\end{array}$

5.57

nd

nd

F6 $164.15 \quad n$

nd

nd

nd

1-Penten-3-ol

F7

1-Pentanol

F8 $\quad 31.30$

nd

29.91

20.25

2-Heptanol

F9

(E)-2-Hexen-1-ol

F10

19.48

23.68

34.26

25.38

(Z)-2-Hexen-1-ol

F11

180.10

nd

$$
\text { nd }
$$

nd

1-Hexanol

(Z)-3-Hexen-1-ol

F12

nd

118.08

121.28

96.64

1

F12 nd

F13

nd

F14 97.43

142.46

296.40

121.48

1-Heptanol

F15

7.08

F16 20.08

nd

12.51

nd

2-Nonanol

(1R)-1,7,7-trimethyl-bicyclo[2.2.1] heptan-2-ol

F17 91.52

271.34

494.37

298.30

3,7-Dimethyl-1,6-octadien-3-ol

F18 33.66

F19 9.45

84.29

84.30

37.52

1-Octanol

F20

4-Methyl-5-hexen-2-ol

F20 nd

1-Nonanol

F21

F22

14.17

(Z)-3-nonen-1-ol

(R)-3,7-dimethyl-6-octen-1-ol

nd

nd

nd

3,7-Dimethyl-2,6-octadien-1-ol

F24

42.52

16.37

20.67

15.66

Benzyl alcohol

F25 21.85

$$
\text { nd }
$$

5.92

nd

12.89

nd

nd

nd

nd

nd

nd

nd

nd

nd

Phenylethyl alcohol

F26

18.30

36.22

10.33

11.07

\section{Others}

2-Ethyl-furan

F27

F28

F29

4-(2,6,6-trimethyl-1-cyclohexen-1-yl)-3-buten-2-one

6-Methyl-5-hepten-2-one

Caryophyllene

$\alpha$-Caryophyllene

$\alpha$-Farnesene

Caryophyllene oxide

2-Tridecanone

2-Pentadecanone

8-Heptadecene

Cyclopentadecanone

Cyclotridecanone

(1R)- 1,7,7-trimethyl-Bicyclo[2.2.1]heptan-2-one

nd, not detected

$\begin{array}{lll}8.01 & 11.42 & 13.23\end{array}$

nd $\quad$ nd $\quad 4.86$

\begin{tabular}{lllll} 
F27 & 7.68 & nd & nd & 6.75 \\
F28 & nd & nd & nd & 5.67 \\
F29 & 10.04 & nd & nd & nd \\
F30 & nd & 79.42 & 76.14 & 133.09 \\
F31 & nd & 154.30 & 343.72 & 130.39 \\
F32 & nd & 20.20 & 46.23 & 17.82 \\
F33 & nd & 45.63 & 306.74 & 32.12 \\
F34 & nd & 9.06 & 14.14 & 5.67 \\
F35 & nd & 372.35 & 722.24 & 277.24 \\
F36 & nd & 36.92 & 204.49 & 19.44 \\
F37 & nd & 0.00 & 83.21 & 0.00 \\
F38 & nd & 117.03 & 440.53 & 54.53 \\
F39 & nd & 0.00 & 26.65 & 9.72 \\
F40 & nd & 24.03 & 46.77 & 23.76 \\
\hline
\end{tabular}

$\begin{array}{llll}\text { F31 nd } & 154.30 & 343.72 & 130.39\end{array}$

\begin{tabular}{lllll} 
F27 & 7.68 & nd & nd & 6.75 \\
F28 & nd & nd & nd & 5.67 \\
F29 & 10.04 & nd & nd & nd \\
F30 & nd & 79.42 & 76.14 & 133.09 \\
F31 & nd & 154.30 & 343.72 & 130.39 \\
F32 & nd & 20.20 & 46.23 & 17.82 \\
F33 & nd & 45.63 & 306.74 & 32.12 \\
F34 & nd & 9.06 & 14.14 & 5.67 \\
F35 & nd & 372.35 & 722.24 & 277.24 \\
F36 & nd & 36.92 & 204.49 & 19.44 \\
F37 & nd & 0.00 & 83.21 & 0.00 \\
F38 & nd & 117.03 & 440.53 & 54.53 \\
F39 & nd & 0.00 & 26.65 & 9.72 \\
F40 & nd & 24.03 & 46.77 & 23.76 \\
\hline
\end{tabular}

$\begin{array}{llll}\text { F33 nd } & 45.63 & 306.74 & 32.12\end{array}$

$\begin{array}{llll}\text { F34 nd } & 9.06 & 14.14 & 5.67\end{array}$

$\begin{array}{lllll}\text { F35 nd } & 372.35 & 722.24 & 277.24\end{array}$

$\begin{array}{llll}\text { F36 nd } & 36.92 & 204.49 & 19.44\end{array}$

$\begin{array}{llll}\text { F37 nd } & 0.00 & 83.21 & 0.00\end{array}$

$\begin{array}{llll}\text { F38 nd } & 117.03 & 440.53 & 54.53\end{array}$

$\begin{array}{llll}\text { F39 } & \text { nd } & 0.00 & 26.65\end{array}$

$\begin{array}{lllll}\text { F40 nd } & 24.03 & 46.77 & 23.76\end{array}$




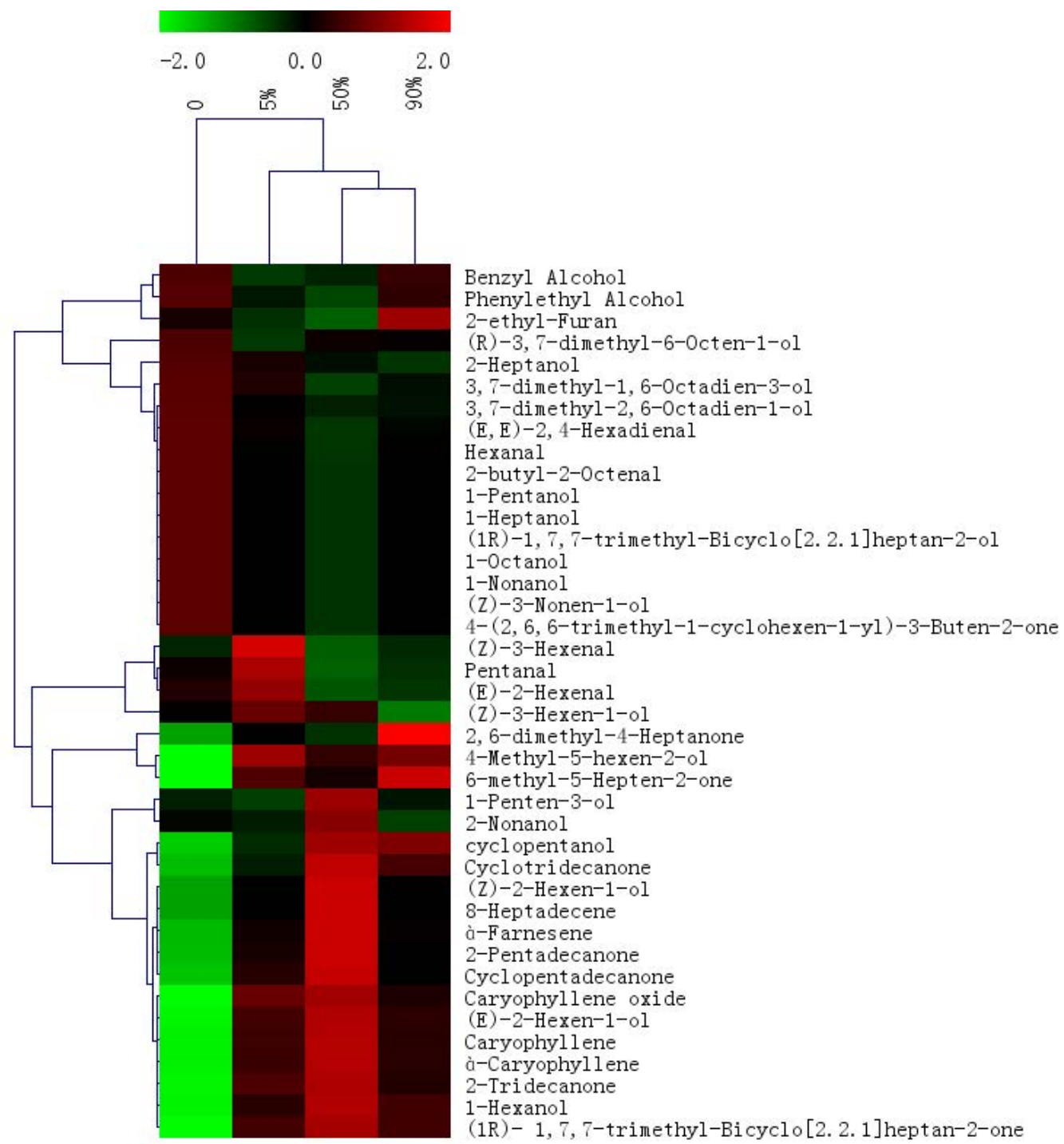

FIGURE 3

Heatmap of the concentration of volatiles in developing flowers Note: 0, 5, 50, 90 (percentage of blooming)

Alcohols were the most abundant class of compounds present in the leaves. Volatile profiles in the leaves were clustered into four groups (Fig. 5), and the four groups of volatiles separated leaves into two different development stages. Fig. 5 reveals that leaves at four weeks before flowering had high concentrations of polymers or more substituent aldehydes and alcohols. The concentrations of 1-heptanol, 2-methylbicyclo[2.2.2] octan-1-ol, 3,7-dimethyl-1,6-octadien-3-ol, 1-octanol, 3,3-dimethyl-4-heptanol, 1-undecanol, 2-pentanol and 1-nonanol were abundant at this stage. C5 and C6 compounds such as 1-hexanol, 1-pentanol, (E)-2-hexenal, (E)-2-pentenal and (Z)-3-hexen-1-ol became obviously abundant from six to 10 weeks after anthesis, although there also were some polymeric compounds including 2,3-dimethyl-1-butanol and (E)-3,7-dimethyl-2,6-octadienal.

PCA analysis revealed that the most clear separation was noted for samples collected at four and two weeks before anthesis, whereas other sampling points are grouped quite closely together. As above, polymer or more substituent aldehydes and alcohols separated leaves sampled four weeks before anthesis from other samples. Leaves sampled at two weeks before anthesis contained more unsaturated alcohols and some unsaturated oxygen heterocyclic compounds. (Z)-3-hexen-1-ol, 1-hexanol, (Z)-2-hexen-1-ol, 1-octen-3-ol, 1-pentanol, 2,3-dimethyl-1-butanol, benzyl alcohol, (Z/E)-3/6-nonen-1-ol, (s)-3-ethyl-4-methyl-pentanol, 2-methyl-4-pentenal and (E)-2-hexenal contributed more to the composition of volatiles in leaves sampled at 10 weeks after anthesis (Fig. 6). This result was consistent with the hypothesis that $\mathrm{C} 6$ compounds were major contributors to the composition of volatiles in mature leaves (i.e., 10 weeks after anthesis).

\section{Activity of ADH and HPL in different tissues}

$\mathrm{ADH}$ and HPL activity in the leaves, flowers and grape skins is shown in Fig. 7. In the grape skin there was high $\mathrm{ADH}$ activity at the early stage of berry development, and it peaked at eight weeks after anthesis, which corroborated several previous studies (Terrier et al., 1996; Tesnière \& Verriès, 2000). In contrast, the activity of both 13-HPL and 9-HPL was low, but they demonstrated a similar trend, with a slight increase (peaking 10 and 12 weeks after flowering) followed 
TABLE 3

Volatile compounds in leaves during development in 2012.

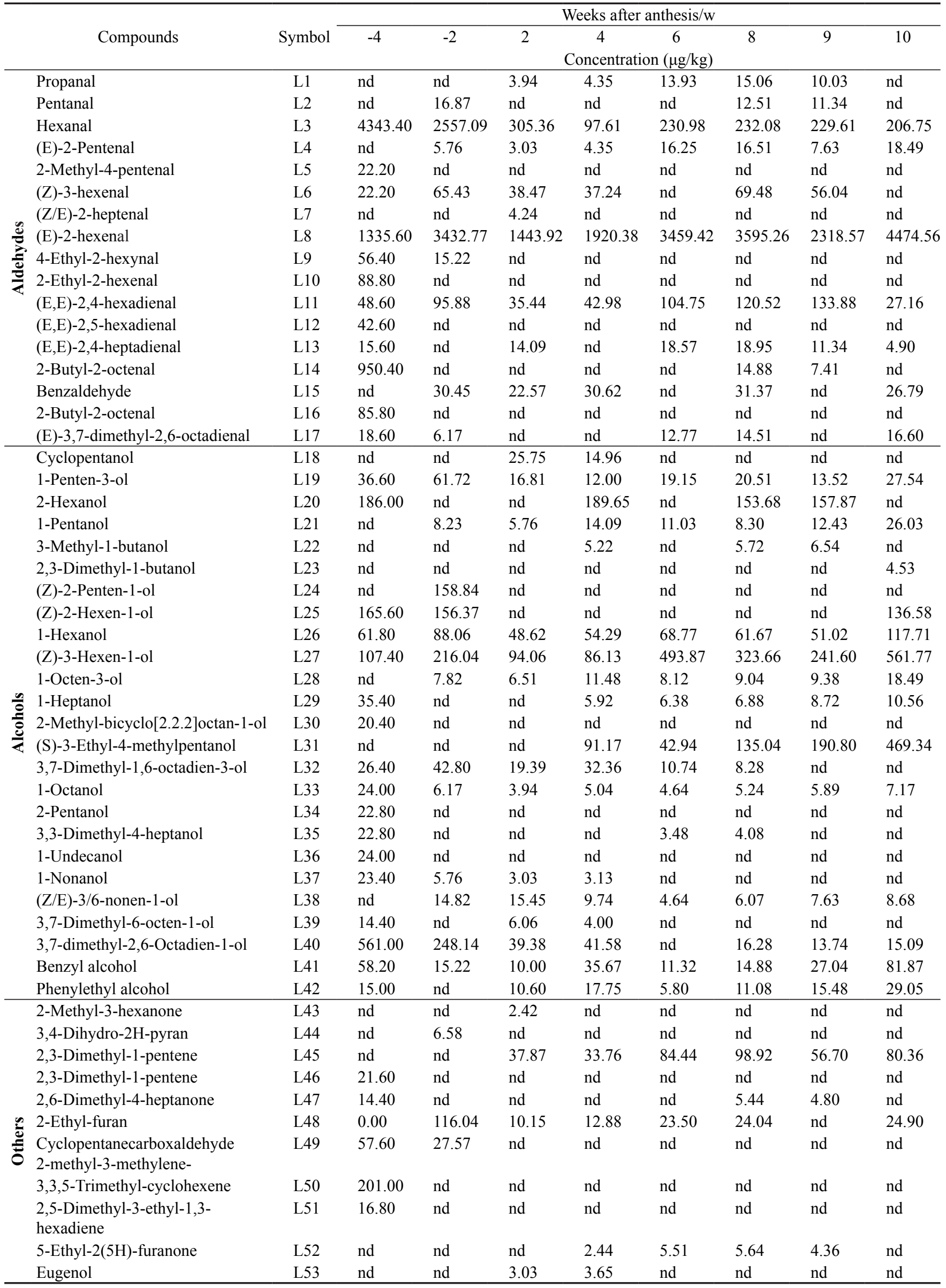

nd, not detected 
by a decline to the initial level during the maturation of the berry (Fig. 7a).

The activity of these enzymes in flowers displayed a different trend. The activity of ADH and 9-HPL was dynamic until the full-bloom stage, with a continuous increase (peaking at $90 \%$ blooming), whereas 13-HPL activity maintained a low but stable level during the development of the flowers (Fig. 7b). In the leaves, the activity of three
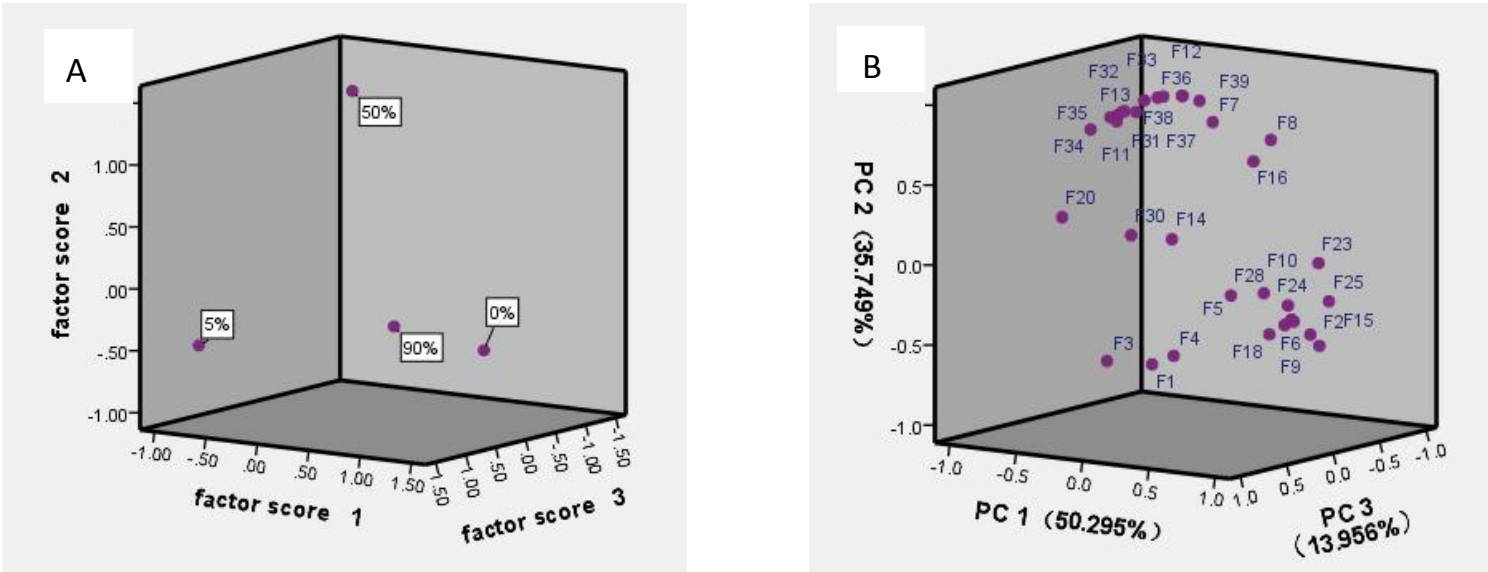

FIGURE 4

Principle component analysis of volatile compounds of grape flowers.

A. PCA score plot. B. Loading plot of components 1, 2 and 3. Note: "F" refers to volatiles in flowers. For details, refer to Table 2.

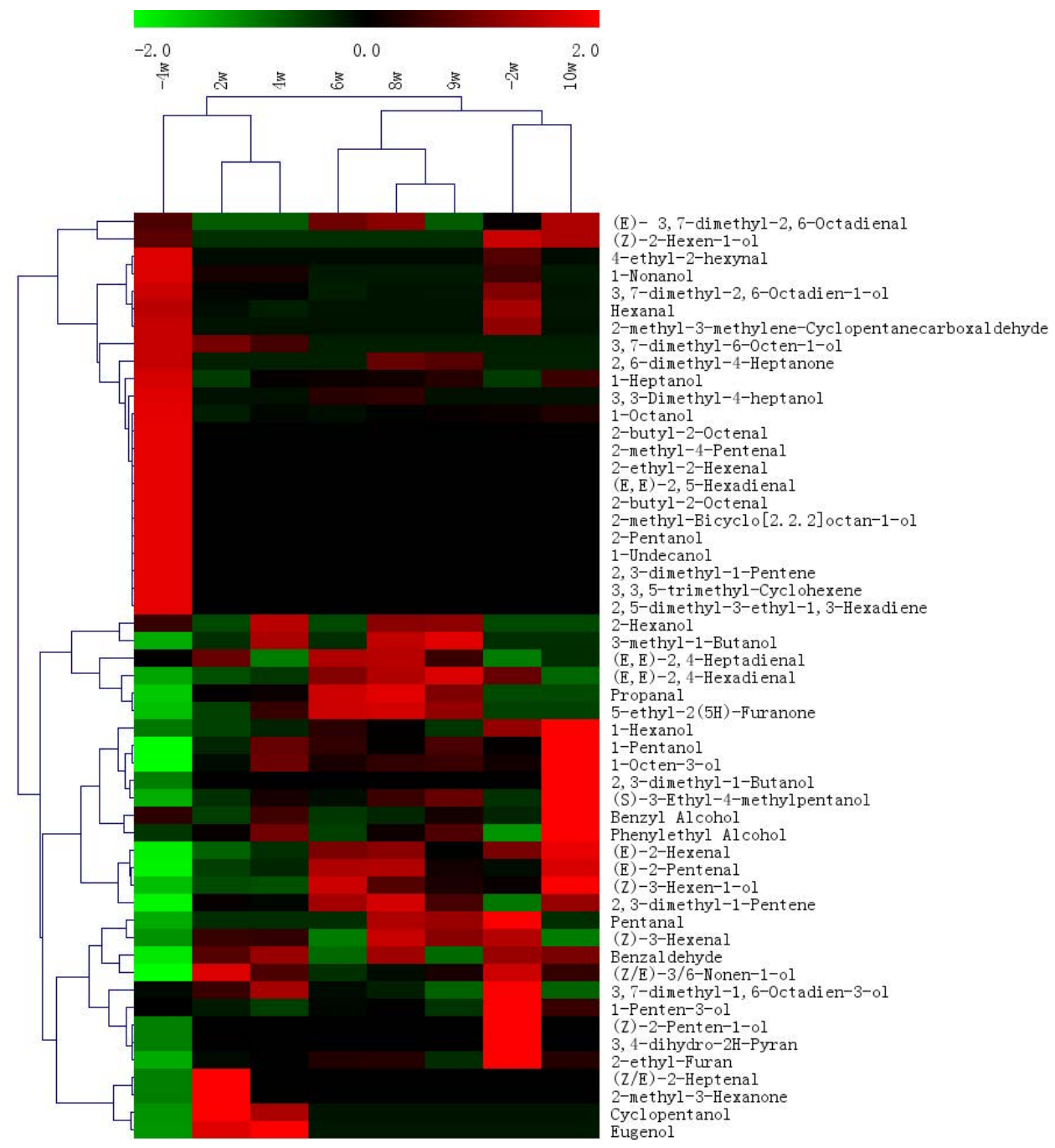

FIGURE 5

Heatmap of volatiles in developing leaves. Note: W (weeks after anthesis) 
enzymes followed an interesting trend. ADH and 9-HPL were more active than 13-HPL, but they all decreased with the development of the leaves (Fig. 7c).

The highest activities of 13-HPL, 9-HPL and ADH occurred in the grape skin, flowers and grape skin respectively. The activity of 13-HPL did not change much in the developing flowers and leaves. The activity of 9-HPL was much higher in the flowers and leaves than in the skins. The activity of ADH was obviously high in these three tissues compared to that of the HPLs. In this paper, we report that the activity of ADH and 9-HPL decreased in the leaves during anthesis (-2 to 2 weeks after anthesis), while they increased in the flowers during the entire process of anthesis. The activity of ADH increased until eight weeks after anthesis in the grape skins. ADH catalysed the conversion of aldehydes to alcohols (Chen \& Chase Jr, 1993; Speirs et al., 1998), and exhibited high activity during berry development (Tesnière et al., 1993; 2006; Köllner et al., 2008). The results on ADH activity were in accordance with the results above. Furthermore, Chen et al. (2015) reported that 9-HPL activity was approximately twice as high as that of 13-HPL in cucumber fruit and that 13-HPL activity decreased with the development of fruit, although 9-HPL activity increased. In this paper, the same trend of 9-HPL and 13-HPL activity as in Chen et al.'s report was tracked in the grape flowers, but was not in the grape skins. We supposed that 13-HPL and 9-HPL activity first increased and then decreased during blossoming and fruit setting.

\section{Correlation analysis of enzyme activity and volatiles}

Fluctuations in the concentrations of $\mathrm{C} 5$ and $\mathrm{C} 6$ are shown in Fig. 8. Generally speaking, the content of $\mathrm{C} 5$ maintained a low level in all three tissues, which may be a result of the weak activity of 13-HPL. C5 volatiles were synthesised by the homolytic mechanism of 13-HPL (Grechkin, 1998; Salch et al., 1995.), while C5 was more abundant in the leaves than in the grape skins and flowers. The concentration of C5 decreased rapidly at the first three sampling dates, and increased slightly later on in the leaves, whereas it kept increasing in the flowers and even in grape skins until nine weeks after anthesis. The concentration of C5 stayed at a stable level in the grape skins from nine to 12 weeks after anthesis, while the concentration of C6 started increasing sharply from nine weeks.

There was quite a significant increase in C6 compounds in the grape skin from nine to 12 weeks, whereas the concentrations decreased later. The concentration of C6 decreased obviously in the flowers and leaves at the first three sampling dates, and they all increased slightly later (Fig. 8). According to previous studies, the C6 content has a direct relationship with the activity of 13-HPL in other species. C6 aldehydes and C12 oxyacids are formed through the heterolytic mechanism of 13-HPL (Blee, 1998; Grechkin, 1998; Mita et al., 2005). Our study showed that the concentration of C6 increased (peaking at 12 weeks) with increasing 13-HPL activity (peaking at 10 weeks) in the grape skins. It seems that both $\mathrm{C} 6$ and $\mathrm{C} 5$ were formed by the catalysis of 13-HPL, while they were not formed at the same time in the grape skins.

The principal alcohols gradually increased in the grape skin with grape development (peaking at 16 weeks) (Fig. 1), which is consistent with high ADH activity, but they may also be synthesised by other metabolic pathways, such as those involved in amino acid metabolism (Sanz et al., 1996). The trend for ADH is consistent with other reports (Van Der Straeten et al., 1991; Echeverria et al., 2004).

A high terpene content was detected in the flowers, which is consistent with the synthesis of terpenes in Arabidopsis (Echeverria et al. 2004) and Antirrhinum majus (Dudareva et al., 2003); therefore, the formation of terpenes may exhibit tissue specificity. The correlation of volatiles in the leaves, flowers and berries and the conjecture of molecule transfer among tissues necessitate further study on the transfer mechanism.

Pearson's correlation analysis was performed on the concentration of volatile components and the activity of 13HPL, 9-HPL and ADHs. The results are shown in Table 4. More kinds of volatile compounds in the leaves correlated with the activity of the three enzymes than in the flowers and grape skins. Furthermore, the concentration of 3,7-dimethyl1,6-octadien-3-ol was positively correlated with the activity of 13-HPL $(p<0.01)$ and 9-HPL $(p<0.05)$, and negatively correlated with activity of ADHs $(P<0.05)$ in the leaves, whereas the concentration was negatively correlated with
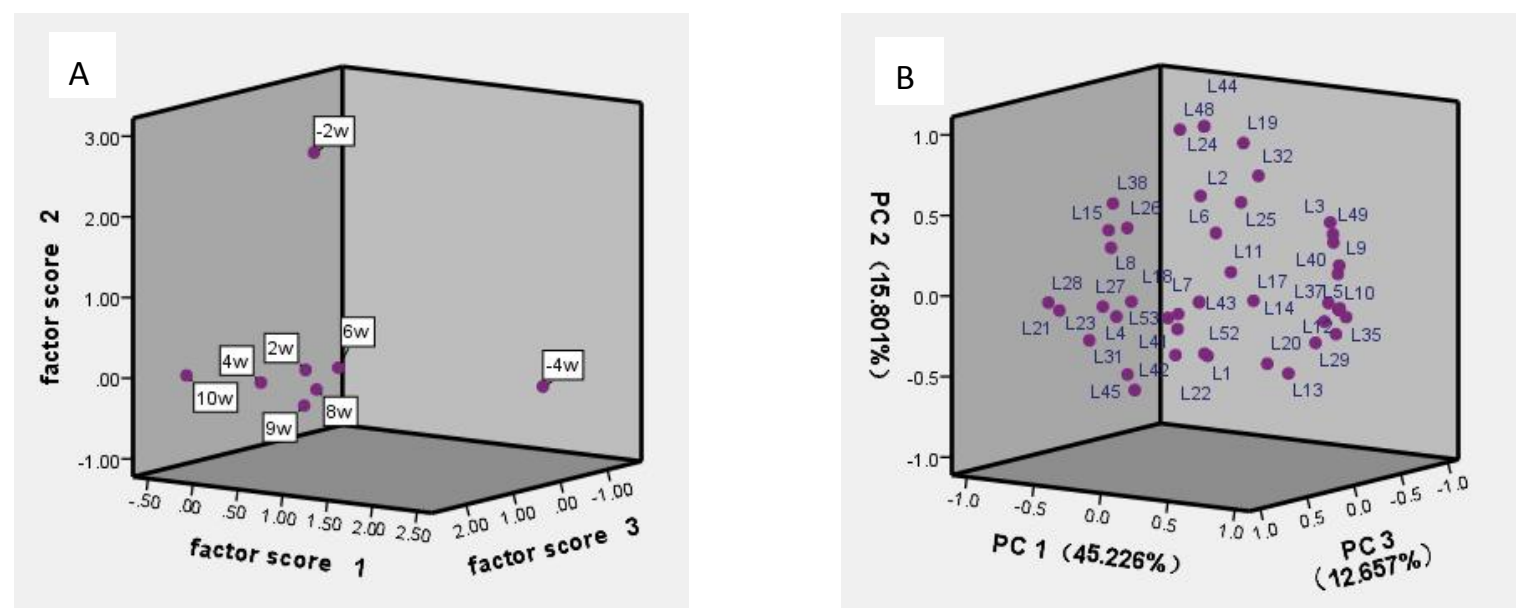

FIGURE 6

Principle component analysis of volatile compounds of leaves. A. PCA score plot. B. Loading plot of components 1, 2 and 3. Note: "L" refers to volatiles in leaves. For detail, refer to Table 3. 
a

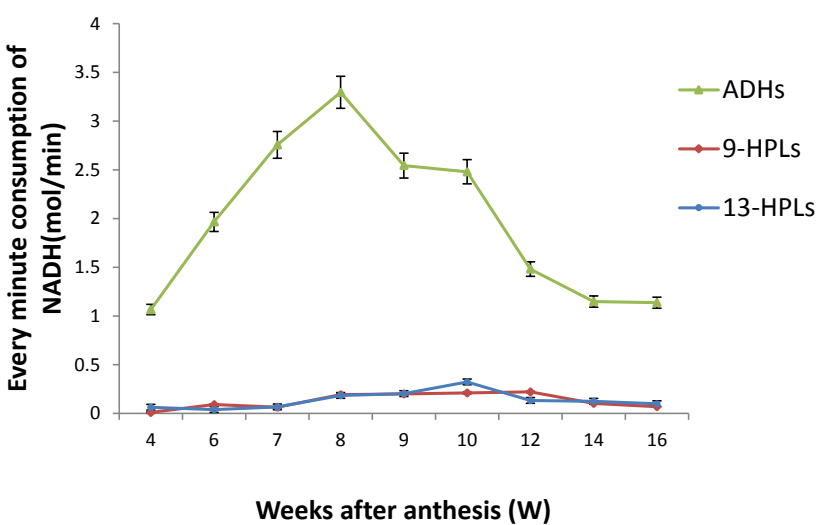

b

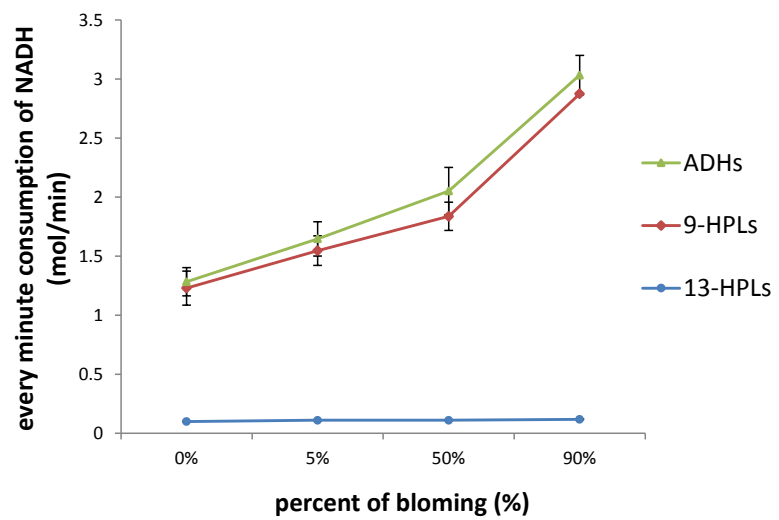

c

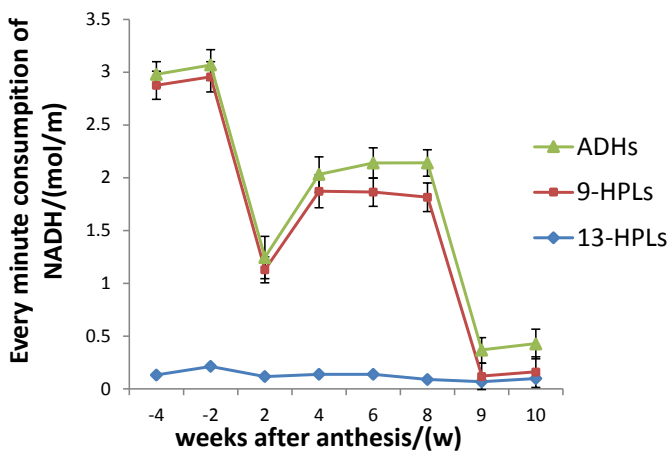

FIGURE 7

Changes in HPLs, ADHs activity during tissues development. A: Changes of activity in grape skin; B: Changes of enzyme activity in developing flowers; C: Changes of enzyme activity in developing leaves.

TABLE 4

Results of Pearson's r correlation analysis between volatile concentration and activity of 13-HPL, 9-HPL and ADHs enzyme.

\begin{tabular}{|c|c|c|c|c|}
\hline Tissue & Compounds & 13-HPL & 9-HPL & ADHs \\
\hline \multirow[t]{11}{*}{ Leaf } & Propanal & -0.449 & -0.168 & $0.747^{*}$ \\
\hline & Hexanal & 0.493 & $0.707^{*}$ & -0.631 \\
\hline & (E)-2-Pentenal & -0.328 & -0.42 & $0.899^{* *}$ \\
\hline & (Z)-2-Penten-1-ol & $0.820^{*}$ & 0.49 & -0.409 \\
\hline & (Z)-3-Hexen-1-ol & -0.217 & -0.407 & $0.755^{*}$ \\
\hline & (S)-3-Ethyl-4-methylpentanol & -0.529 & $-0.744^{*}$ & 0.573 \\
\hline & 3,7-Dimethyl-1,6-octadien-3-ol & $0.877^{* * *}$ & $0.810^{*}$ & $-0.789^{*}$ \\
\hline & 3,4-Dihydro-2H-pyran & $0.820^{*}$ & 0.49 & -0.409 \\
\hline & 2,3-Dimethyl-1-pentene & -0.638 & -0.569 & $0.950^{* *}$ \\
\hline & 2-Ethyl-furan & $\mathbf{0 . 8 0 3}^{*}$ & 0.446 & -0.23 \\
\hline & 5-Ethyl-2(5H)-furanone & -0.418 & -0.147 & $0.767^{*}$ \\
\hline \multirow[t]{4}{*}{ Flower } & Cyclopentanol & 0.57 & 0.6 & $0.96^{*}$ \\
\hline & 2-Heptanol & $-0.983^{*}$ & -0.8 & -0.686 \\
\hline & (Z)-3-Hexen-1-ol & -0.876 & $-0.983^{*}$ & -0.413 \\
\hline & Caryophyllene & $1 * *$ & 0.894 & 0.641 \\
\hline \multirow[t]{5}{*}{ Berry skin } & 1-Penten-3-ol & 0.654 & $0.704^{* *}$ & -0.18 \\
\hline & 2-Hexanol & -0.651 & -0.527 & $-0.762^{* *}$ \\
\hline & (Z)-2-Penten-1-ol & 0.559 & $0.702^{*}$ & -0.206 \\
\hline & 3,7-Dimethyl-1,6-octadien-3-ol & $-0.746^{*}$ & $-0.689^{*}$ & -0.632 \\
\hline & D-limonene & $0.706^{*}$ & 0.244 & 0.013 \\
\hline
\end{tabular}

$* *$ Values in bold are significantly correlated at $\mathrm{p}<0.01 . *$ Values in bold are significantly correlated at $\mathrm{p}<0.05$. The absence of ${ }^{*} *$ ' indicates $\mathrm{P}>0.05$. 

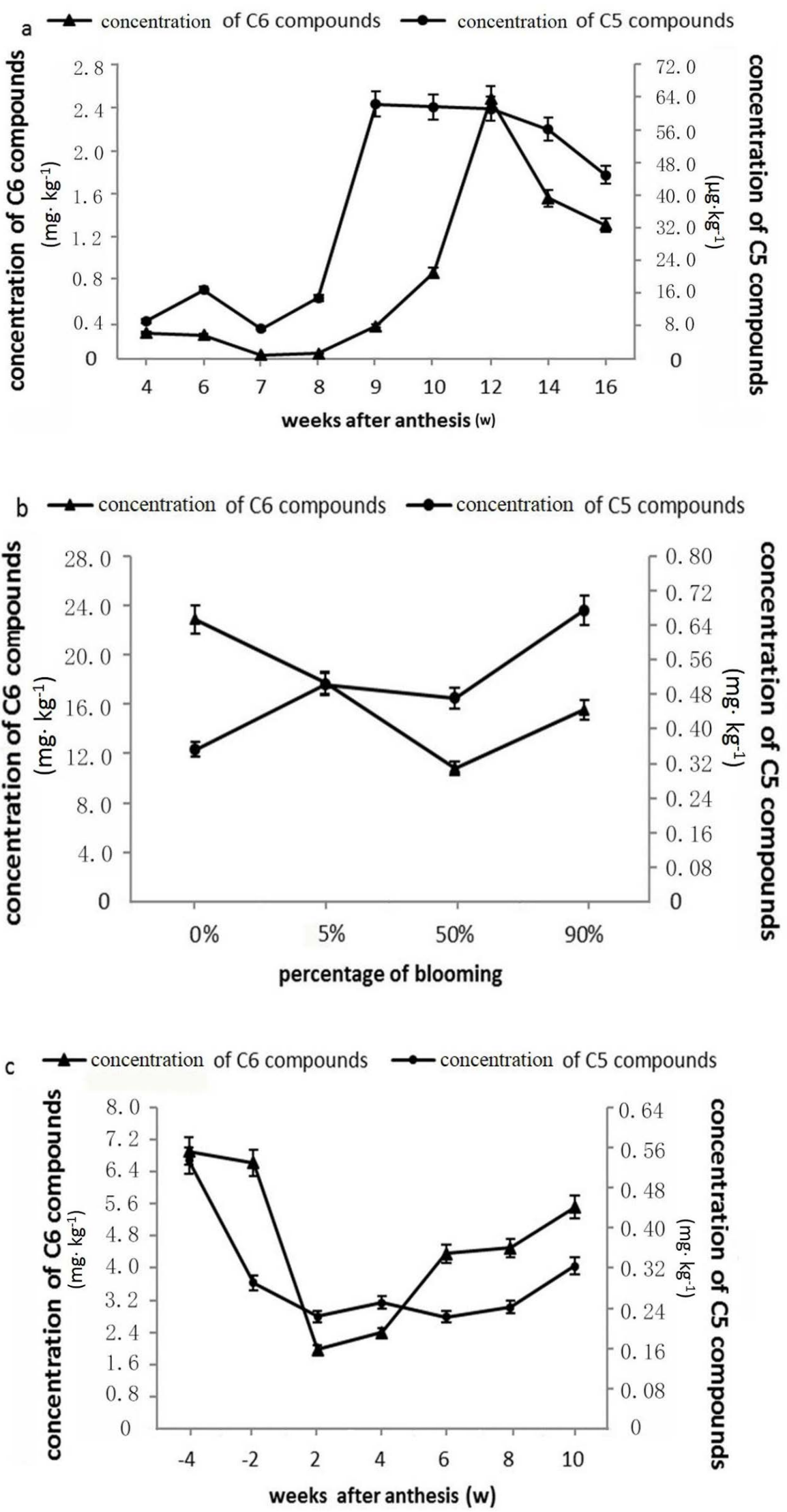

FIGURE 8

Concentration of six-carbon compounds and five-carbon compounds in (a) grape skin; (b) flower; (c) leaves 


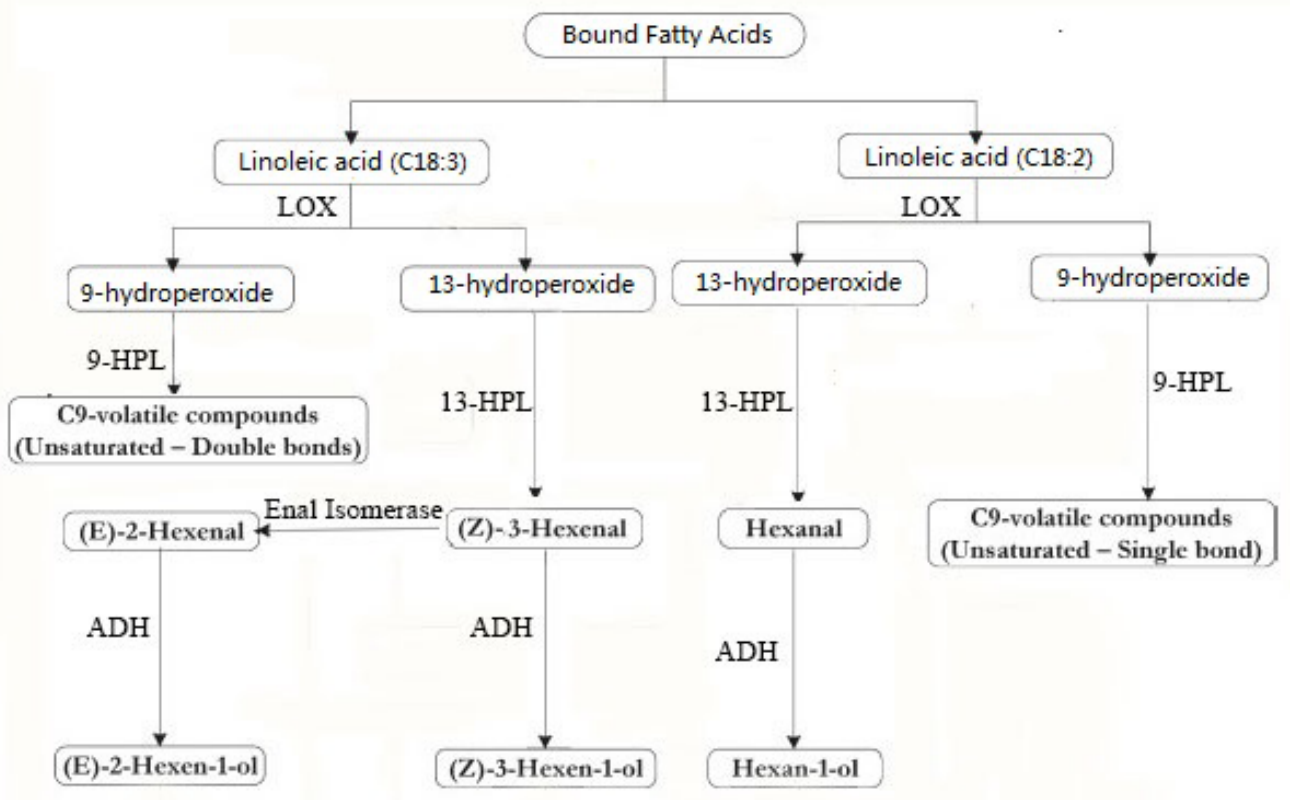

FIGURE 1S

Schematic drawing of the GLV pathway in plants

TABLE S1

Standard curves of characteristic volatiles.

\begin{tabular}{|c|c|c|c|c|}
\hline No. & Retention time/min & English name & Standard curve equation & $\mathrm{R}^{2}$ \\
\hline 1 & 8.94 & Pentanal & $y=40.89 x-12.92$ & 0.994 \\
\hline 2 & 10.49 & Butanoic acid, ethyl ester & $y=2.443 x+13.16$ & 0.998 \\
\hline 3 & 11.71 & Hexanal & $y=46.15 x-603.0$ & 0.995 \\
\hline 4 & 13.09 & (E)-2-Pentenal & $y=20.85 x+24.13$ & 0.996 \\
\hline 5 & 14.72 & Heptanal & $y=4.673 x+37.45$ & 0.998 \\
\hline 6 & 15.79 & (E)-2-Hexenal & $y=12.70 x+161.7$ & 0.997 \\
\hline 7 & 16.58 & 1-Pentanol & $y=71.10 x-8.869$ & 0.998 \\
\hline 8 & 18.56 & (Z)-2-Penten-1-ol & $y=79.66 x+22.38$ & 0.997 \\
\hline 9 & 19.62 & 1-Hexanol & $y=13.95 x+82.38$ & 0.997 \\
\hline 10 & 21.1 & (E)-2-Hexen-1-ol & $y=14.16 x+82.27$ & 0.998 \\
\hline 11 & 28.47 & 1-Nonanol & $y=0.916 x+8.604$ & 0.997 \\
\hline 12 & 30.02 & (E/Z)-6-Nonen-1-ol & $y=3.436 x+19.65$ & 0.997 \\
\hline
\end{tabular}

the activity of both 13-HPL and 9-HPL $(P<0.05)$ in the grape skins. It appears that the correlation of the activity of the enzyme and the concentration of volatile compounds exhibited tissue specificity. The concentrations of 1-penten3-ol and (Z)-2-penten-1-ol were positively correlated with the activity of 9-HPL in the berry skin. In addition, the concentration of 2-hexanol was negatively correlated with the activity of ADHs. The concentration of (Z)-3-hexen-1-ol in the flowers was negatively correlated with the activity of 9-HPL, but it was positively correlated with the activity of ADHs in the leaves.

\section{CONCLUSIONS}

The multivariate analysis of the concentrations of volatiles in Cabernet Sauvignon grapes revealed that the volatile profiles were dramatically different among the grapes, leaves and flowers. The volatile profiles of the grape skins were found to be more complex, with not only more types of volatile compounds detected, but also higher concentrations, especially of C6 compounds, resulting in a higher total overall at 16 weeks after anthesis. C6 compounds in grapes are also known to be direct precursors of the formation of some pleasant esters in wines. In the leaves, polymer alcohols and ketones were gradually broken down, whereas some C6 and $\mathrm{C} 5$ alcohols accumulated in old leaves. In the flowers, aldehydes and alcohols were major contributors at the bud stage, but most of these compounds were not retained in the full blooming flowers. The accumulation of alcohols in the grape skin was apparent, which correlated with the high activity of ADHs. This is consistent with the documented 
pathway of fatty acid oxidation, LOX-HPL. In addition, the decreasing concentration of volatiles in the leaves might be caused by transportation from the leaves to the grapes, which is in need of further study.

The activity of 13-HPL was low during the growing season, whereas the content of C6 was noticeably high. As we hypothesised, the activity of 13-HPL occurred at a stage we did not examine. Generally, the activity of 9-HPL in the leaves and flowers was high, but few C9 compounds were detected in these two kinds of tissue. This might be because the C9 compounds were unstable and were degraded quickly.

\section{LITERATURE CITED}

Anthon, G.E. \& Barrett, D.M., 2003. Thermal inactivation of lipoxygenase and hydroperoxytrienoic acid lyase in tomatoes. Food Chem. 81, 275-279.

Baumes, R., Bayonove, C., Barillère, J. M., Escudie, R. \& Cordonnier, R., 1988. La macération pelliculaire dans la vinification en blanc. Incidence sur la composante volatile des moûts Connaissance de la Vigne et du Vin. Journal International des sciences de la vigne, 32, 209-223.

Bestmann, H.J., Winkler, L. \& Von, H.O., 1997. Headspace analysis of volatile flower scent constituents of bat-pollinated plants. Phytochem. 46, 1169-1172.

Blee, E., 1998. Phytooxylipins and plant defense reactions. Prog. Lipid Res. $37,33-72$.

Cynthia, M.M. \& Kenji M., 2014. The importance of lipoxygenase control in the production of green leaf volatiles by lipase-dependent and independent pathways. Plant Biotechnol. 31, 445-452.

Chen, A.R. \& Chase Jr., T., 1993. Alcohol dehydrogenase 2 and pyruvate decarboxylase induction in ripening and hypoxic tomato fruit. Plant Physiol. Bioch. 31, 875-885.

Chen, S.X., Zhang, R.R., Hao, L.N., Chen, W.F. \& Cheng, S.Q., 2015. Profiling of volatile compounds and associated gene expression and enzyme activity during fruit development in two cucumber cultivars. Plos One 3, $1-22$.

Coelho, E., Rocha, S.M., Barros, A.S., Delgadillo, I. \& Coimbra, M.A., 2007. Screening of variety and pre-fermentation-related volatile compounds during ripening of white grapes to define their evolution profile. Anal. Chim. Acta 597, 257-264.

Defilippi, B.G., Kader, A.A. \& Dandekar, A.M., 2005. Apple aroma: Alcohol acyltransferase, a rate limiting step for ester biosynthesis, is regulated by ethylene. Plant Sci. 168, 1199-1210.

Delphia, C.M., Mescher, M.C. \& De Moraes, C.M., 2007. Induction of plant volatiles by herbivores with different feeding habits and the effects of induced defenses on host-plant selection by thrips. J. Chem. Ecol. 33, 997-1012.

Dudareva, N., Martin, D., Kish, C.M., Kolosova, N., Gorenstein, N., Faldt, J., Miller, B. \& Bohlmann, J., 2003. (E)-beta-ocimene and myrcene synthase genes of floral scent biosynthesis in snapdragon: Function and expression of three terpene synthase genes of a new terpene synthase subfamily. Plant Cell 15, 1227-1241.

Echeverria, G., Graell, J., López, M. \& Lara, I., 2004. Volatile production, quality and aroma-related enzyme activities during maturation of 'Fuji' apples. Postharvest Biol. Tec. 31, 217-227.

Gomez, E., Martinez, A. \& Laencina, J., 1995. Changes in volatile compounds during maturation of some grape varieties. J. Sci. Food Agr. $67,229-233$
Grechkin, A., 1998. Recent developments in biochemistry of the plant lipoxygenase pathway. Prog. Lipid Res. 37, 317-352.

Hashizume, K. \& Samuta, T., 1997. Green odorants of grape cluster stem and their ability to cause a wine stemmy flavor. J. Agr. Food Chem. 45, 1333-1337.

Hatanaka, A., 1993. The biogeneration of green odour by green leaves. Phytochem. 34, 1201-1218.

Jiang, W.G., Li, J.M., Xu, Y., Fan, W. \& Yu, Y., 2011. Analysis of aroma components in four red grape varieties. Food Sci. 32(6), 225-229.

Köllner, T.G., Held, M., Lenk, C., Hiltpold, I., Turlings, T.C., Gershenzon, J. \& Degenhardt, J., 2008. A maize (E)- $\beta$-caryophyllene synthase implicated in indirect defense responses against herbivores is not expressed in most American maize varieties. Plant Cell 20, 482-494.

Kalua, C.M. \& Boss, P.K., 2009. Evolution of volatile compounds during the development of Cabernet Sauvignon grapes (Vitis vinifera L.). J. Agr. Food Chem. 57, 3818-3830.

Matsui, K., Minami, A., Hornung, E., Shibata, H., Kishimoto, K., Ahnert, V., Kindl, H., Kajiwara, T. \& Feussner, I., 2006. Biosynthesis of fatty acid derived aldehydes is induced upon mechanical wounding and its products show fungicidal activities in cucumber. Phytochem. 67, 649-657.

Matsui, K., Ujita, C., Fujimoto, S.H., Wilkinson, J., Hiatt, B., Knauf, V., Kajiwara, T. \& Feussner, I., 2000. Fatty acid 9- and 13-hydroperoxide lyases from cucumber. FEBS Lett. 481, 183-188.

Mita, G., Quarta, A., Fasano, P., De Paolis, A., Di Sansebastiano, G.P., Perrotta, C., Iannacone, R., Belfield, E., Hughes, R. \& Tsesmetzis, N., 2005. Molecular cloning and characterization of an almond 9-hydroperoxide lyase, a new CYP74 targeted to lipid bodies. J. Exp. Bot. 56, 2321-2333.

Nakamura, S. \& Hatanaka, A., 2002. Green-leaf-derived C6-aroma compounds with potent antibacterial action that act on both gram-negative and gram-positive bacteria. J. Agr. Food Chem. 50, 7639-7644.

Park, S.K., Morrison, J.C., Adams, D.O. \& Noble, A.C., 1991. Distribution of free and glycosidically bound monoterpenes in the skin and mesocarp of Muscat of Alexandria grapes during development. J. Agr. Food Chem. 39, 514-518.

Perestrelo, R., Barros, A.S., Rocha, S.M. \& Câmara, J.S., 2011. Optimisation of solid-phase microextraction combined with gas chromatography-mass spectrometry based methodology to establish the global volatile signature in pulp and skin of Vitis vinifera L. grape varieties. Talanta 85, 1483-1493.

Salch, Y. P., Grove, M. J., Takamura, H. \& Gardner, H. W., 1995. Characterization of a C-5,13-cleaving enzyme of 13(S)-Hydroperoxide of linolenic acid by soybean seed. Plant Physiol. 108, 1211-1218.

Sanz, C., Olias, J.M. \& Perez, A., 1996. Aroma biochemistry of fruits and vegetables. Pr. Phyt. Soc. 41, 125-156.

Smith, P., Krohn, R.I., Hermanson, G., Mallia, A., Gartner, F., Provenzano, M., Fujimoto, E., Goeke, N., Olson, B. \& Klenk, D., 1985. Measurement of protein using bicinchoninic acid. Anal. Biochem. 150, 76-85.

Song, J., Shellie, K.C., Wang, H. \& Qian, M.C., 2012. Influence of deficit irrigation and kaolin particle film on grape composition and volatile compounds in Merlot grape (Vitis vinifera L.). Food Chem. 134, 841-850.

Speirs, J., Lee, E., Holt, K., Yong-Duk, K., Scott, N.S., Loveys, B. \& Schuch, W., 1998. Genetic manipulation of alcohol dehydrogenase levels in ripening tomato fruit affects the balance of some flavor aldehydes and alcohols. Plant Physiol. 117, 1047-1058.

Suurmeijer, C.N., Pérez-Gilabert, M., Van der Hijden, H.T., Veldink, G.A. \& Vliegenthart, J.F., 1998. Purification, product characterization and kinetic properties of soluble tomato lipoxygenase. Plant Physiol. Bioch. 36, 657663. 
Terrier, N., Sauvage, F. \& Romieu, C., 1996. Absence de crise respiratoire, induction de l'activité alcool deshydrogénase et diminution de l'acidité vacuolaire lors de la maturation du raisin In Enologie 95, Compte Rendu 5eme Symposium International d'CEnologie. Tec \& Doc Lavoisier, Paris. pp. $24-28$.

Tesnière, C. \& Verriès, C. 2000. Molecular cloning and expression of cDNAs encoding alcohol dehydrogenases from Vitis vinifera L. during berry development. Plant Sci. 157, 77-88.

Tesnière, C.M., Romieu, C. \& Vayda, M.E., 1993. Changes in the gene expression of grapes in response to hypoxia. Am. J. Enol. Vitic. 44, 445-451.

Tesnière, C., Davies, C., Sreekantan, L., Bogs, J., Thomas, M. \& Torregrosa, L., 2006. Analysis of the transcript levels of VvAdh1, VvAdh2 and VvGrip4, three genes highly expressed during Vitis vinifera L. berry development. Vitis $45,75-79$.
Tufariello, M., Capone, S. \& Siciliano, P., 2012. Volatile components of Negroamaro red wines produced in Apulian Salento area. Food Chem. 132 2155-2164.

Van Der Straeten, D., Pousada, R.A.R., Gielen, J. \& Van Montagu, M., 1991. Tomato alcohol dehydrogenase: Expression during fruit ripening and under hypoxic conditions. FEBS Lett. 295, 39-42.

Xiao qing, X., Guo, C., Ling ling, D., Jiang, R., Qiu hong, P., Chang qing, D., \& Jun, W., 2015. Effect of training systems on fatty acids and their derived volatiles in Cabernet Sauvignon grapes and wines of the north foot of Mt. Tianshan. Food Chem. 181, 198-206. 